\title{
SILENT HYDRONEPHROSIS, A HAZARD REVISITED
}

\author{
By Joel S. Rosen, M.D., John B. Nanninga, M.D. and Vincent J. O’Conor, M.D. \\ Midwest Regional Spinal Cord Injury Care System, \\ Chicago, Illinois, U.S.A.
}

Abstract. Six patients with neurogenic bladder secondary to spinal cord injury were seen in our Centre for routine follow-up. All of these individuals had attained the catheter-free state by various means and were, by their standards, functioning very well. They had gone from 6 months to $2 \frac{1}{2}$ years without genito-urinary re-evaluations. One individual had a normal urogram I year after catheter removal and then 2 years later was noted to have bilateral hydronephrosis. Development of silent hydronephrosis in the catheter-free state, its treatment, and a regimen for following patients are discussed.

THE recognition of hydronephrosis following spinal cord injury has been documented in the past by several authorities (Talbot \& Bunts, I940; Hutch \& Bunts, I95I; Damanski \& Gibbon, I956). Damanski and Gibbon stated that hydronephrosis occurred in one-third of a group of patients suffering from spinal cord injury. The changes have been reported to occur as early as 2 months after injury to as long as 8 years later. Ross (I963) has found hydronephrosis to be associated with the neural damage, urinary infection and back pressure; the importance of each factor varying considerably with the individual, Ascoli and Franch (1970) noted hydronephrosis most frequently in patients more than 4 years post trauma. Warning signs of impending hydronephrosis include the onset of urinary tract infection, deterioration of bladder function, increasing residual urine, bladder hypertonia and the appearance of bladder diverticula and reflux. The onset may, however, be insidious and considerable impairment in renal function may occur before the damage is detected.

This paper presents six patients in whom hydronephrosis developed following spinal cord injury. Patients with calculi or tumours were not included. In each patient the individual had been managed initially with an indwelling catheter and then treated by intermittant catheterisation until satisfactory bladder function was obtained. This occurred over a 4 to 6 month period. At the time of follow-up, none of the six individuals had any definite history of genito-urinary symptoms such as fever, haematuria, cloudy urine, lithuria or autonomic dysreflexia. The diagnosis was, in fact, made during an annual check-up or because the patient presented to the clinic in need of a new wheelchair or orthosis.

As the preservation of renal function is the critical issue in deciding on the proper management of the neurogenic dysfunction of the bladder, we believe that the hazards of hydronephrosis in the catheter-free state, when the patient is believed to be doing well, deserves re-emphasis.

\section{Case Material}

Table I summarises the findings in these patients. A brief but pertinent history of each follows. 
TABLE I

Patient

\author{
I. T. C. $\left(\mathrm{C}_{7}, \mathrm{c}\right)$
}

2. A. B. $\left(\mathrm{C}_{5}, \mathrm{c}\right)$

3. P. V. $(T 6$, inc $)$

4. L. D. (TII, c)

5. L. P. $\left(\mathrm{L}_{5}\right.$, inc $)$

6. J. C. (TII, c)
Duration of injury

$24 \mathrm{mo}$

$26 \mathrm{mo}$

$132 \mathrm{mo}$

Io mo

$22 \mathrm{mo}$

$9 \mathrm{mo}$
Appearance of hydronephrosis
Bladder type

and residual*
Infection

$$
\begin{array}{cl}
\text { I8 mo } & \begin{array}{l}
\text { reflex } \\
65 \rightarrow 700 \mathrm{ml} \\
22 \mathrm{mo}
\end{array} \\
\begin{array}{l}
\text { reflex } \\
\text { I00 } \rightarrow 500 \mathrm{ml} \\
\text { reflex } \\
? \rightarrow \text { I000 ml } \\
\text { autonomous } \\
\text { I00 } \rightarrow 50 \mathrm{ml}
\end{array} \\
5 \mathrm{mo} & \begin{array}{l}
\text { autonomous } \rightarrow \text { reflex } \\
60 \rightarrow 75 \mathrm{ml} \\
\text { autonomous } \rightarrow \text { reflex } \\
\text { IصO } \rightarrow \text { I } 25 \mathrm{ml}
\end{array} \\
\text { I4 mo } &
\end{array}
$$

$\mathrm{c}=$ complete.

inc $=$ incomplete.

* Change in residual urine with appearance of hydronephrosis.

Patient I had returned to college following his discharge catheter free from our institution. The urogram was normal (fig. Ia). A period of 15 months had elapsed since his last urological evaluation. The only reported problem during that time was one upper respiratory infection which responded promptly to treatment. At the time of his recheck, he reported a slight increase in spasticity. An excretory urogram revealed typical hydronephrotic changes (fig. Ib). He was treated with an indwelling catheter with subsequent return to normal, as demonstrated by X-ray (fig. Ic). An external sphincterotomy was later performed and at 2 year follow-up he has a stable collecting system and renal function.

Patient 2 had returned to work in the community and was functioning well with no complaints. He did not want to lose any time from his job so he missed his yearly check up. When he finally reported to the clinic it was because of a need for a new upper extremity orthosis. He did report a slight increase in spasticity. The urogram revealed hydronephrosis and the patient had an indwelling catheter inserted. The X-rays have since improved and he is now awaiting sphincterotomy.

Patient 3 was managed initially at another institution and reported that his residual urines were low when discharged. He was referred to our institution for a new lower extremity orthosis. The urogram revealed poor visualisation but some degree of hydronephrosis was noted. The bladder revealed marked trabeculation and slight reflux (fig. 2). The BUN was 46 and the creatinine 3.7, indicating marked renal impairment. This was the only patient with an elevated BUN or creatinine. Subsequently, he underwent insertion of a suprapubic tube.

Patient 4 was the only one whose post-voiding residual urine actually decreased. In order to void, this patient exerted a tremendous amount of intravesical pressure by performing a Valsalva manoeuvre and a very forceful Crede. When the hydronephrosis was discovered, an indwelling catheter was inserted. His X-ray findings have reverted to normal and he is awaiting a bladder neck resection.

Patient 5 had a low level incomplete injury and retained some degree of bladder sensation. He had been successfully decatheterised and at that time had cysto- 

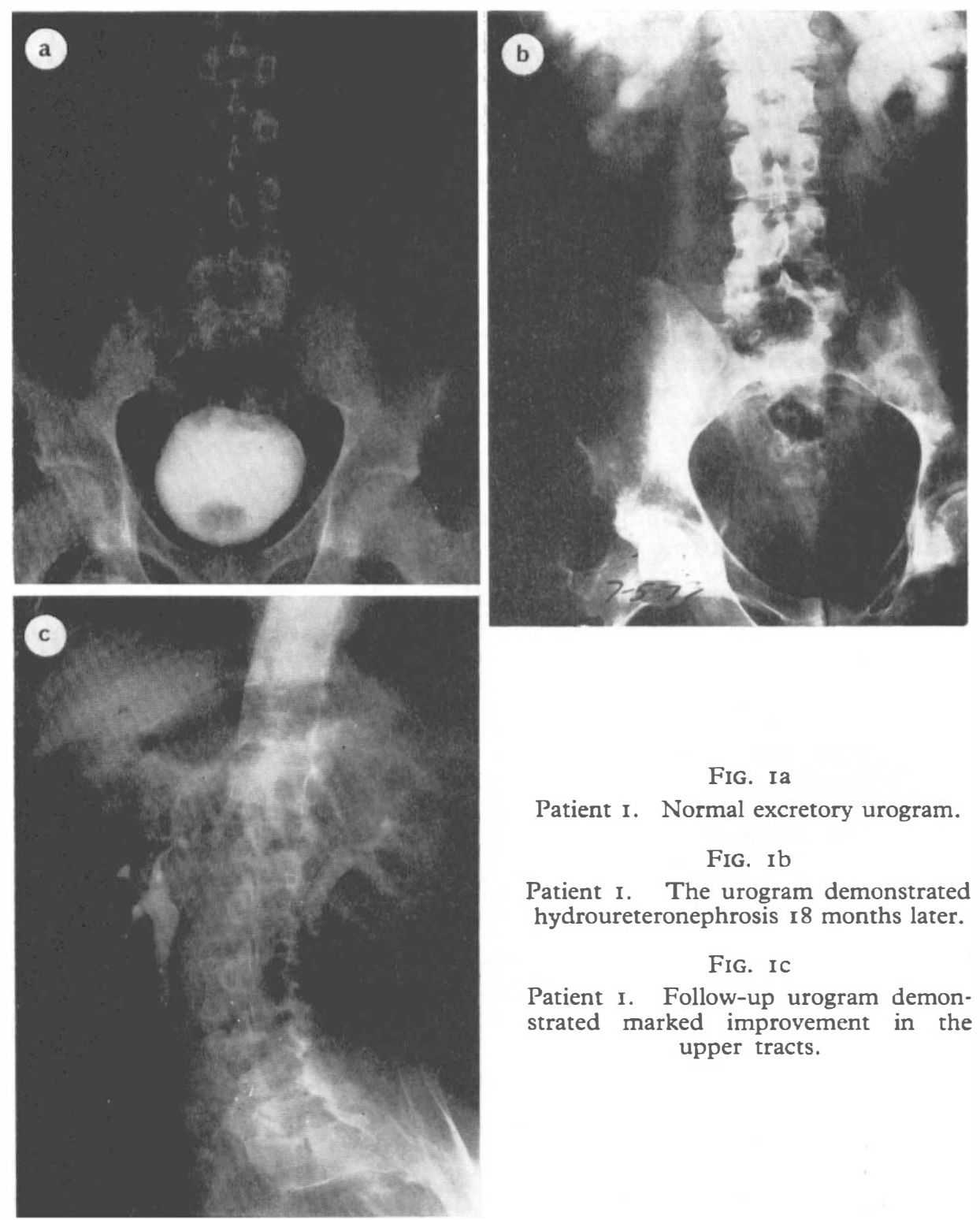

Fig. Ia

Patient I. Normal excretory urogram.

FIG. Ib

Patient I. The urogram demonstrated hydroureteronephrosis 18 months later.

Frg. IC

Patient I. Follow-up urogram demonstrated marked improvement in the upper tracts.

metric evidence of a lower motor neuron (autonomous) type bladder. He first presented to our clinic about 2 years after injury because of a vague feeling of incomplete bladder emptying. An excretory urogram revealed hydronephrosis. A sphincterotomy was performed soon after that and the X-ray appearance has returned to normal.

Patient 6 had functioned in the catheter-free state for 5 months when a routine urogram demonstrated bilateral hydronephrosis. The patient then underwent an external sphincterotomy. There was X-ray improvement but the patient was 

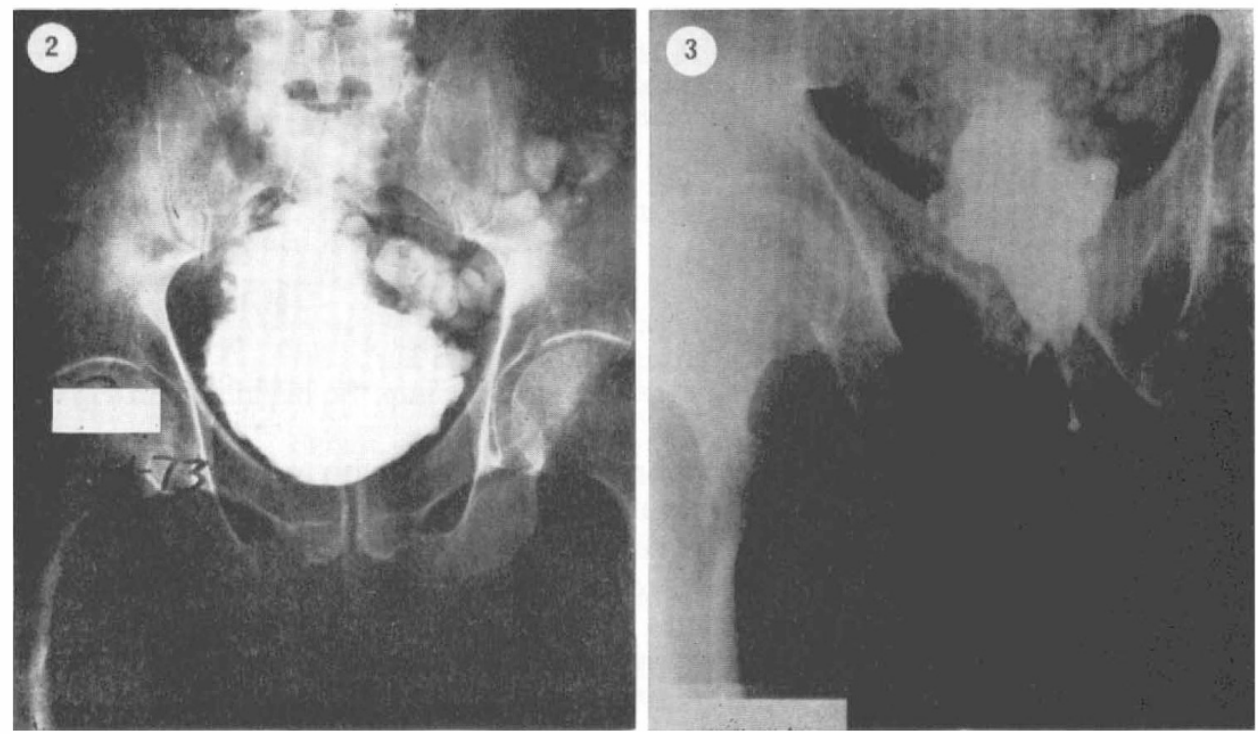

FIG. 2

Patient 3. The cystogram demonstrated marked trabeculation and cellule formation.

Fig. 3

Patient 6. Voiding cystourethrogram revealed small capacity trabeculated bladder with marked narrowing at the external sphincter.

lost to follow-up for 15 months. He then presented to the clinic because of multiple pressure sores. The urogram and cystogram revealed a return of hydronephrosis and obstruction at the external sphincter (fig. 3). Had the patient been seen earlier, the result of an inadequate sphincterotomy might have been avoided. He is currently awaiting repeat sphincterotomy.

Table II summarises the cystometric data from the patients in whom it was available. In the three patients with reflex bladders (T. C., L. D., J. C.) all pressures were above what we consider to be the upper limits of normal.

\section{Discussion}

The six patients presented herein were thought to be progressing satisfactorily when on the basis of follow-up X-rays, bilateral hydronephrosis was found. Only one patient, number 5, noted any symptom directly referable to the urinary tract. However, two patients, numbers I and 2, noted an increase in the degree of spasticity, which seemed to relate to external sphincter obstruction. It was obvious that in four of the patients the degree of bladder outlet obstruction had increased as evidenced by the increased residual urine. Five of the patients demonstrated a reflex type of bladder with characteristic trabeculation. Interestingly, the bladders of two patients changed from autonomous to reflex type. In those patients who underwent sphincterotomy, the characteristic narrowing at the external sphincter was seen on voiding cysto-urethrogram, and perineal muscle EMG revealed an increase rather than a decrease in activity during attempts at voiding (Nanninga et al., 1974). 
TABLE II

$\begin{array}{lrrrr}\text { Patient } & \begin{array}{c}\text { Residual at the time } \\ \text { of hydronephrosis }\end{array} & \mathrm{P}_{\mathrm{r}} & \mathrm{P}_{\mathrm{v}} & \mathrm{P}_{\mathrm{u}} \\ \text { T. C. } & +700 \mathrm{ml} & 25 & \mathrm{I} 20 & \mathrm{I20} \\ \text { L. D. } & 50 \mathrm{ml} & 8 & 30 & 30 \\ \text { L. P. } & 75 \mathrm{ml} & 20 & 72 & 70 \\ \text { J. C. } & +\mathrm{I} 25 \mathrm{ml} & 32 & 63 & 60\end{array}$

$\mathrm{P}_{\mathrm{r}}=$ bladder pressure at rest $(\mathrm{mm} \mathrm{Hg})$.

$\mathrm{P}_{\mathrm{v}}=$ bladder pressure (maximal) during voiding $(\mathrm{mm} \mathrm{Hg})$.

$\mathrm{P}_{\mathrm{u}}=$ retrograde urethral pressure needed to force air into the bladder $(\mathrm{mm} \mathrm{Hg})$.

The appearance of the hydronephrosis associated with neurogenic bladder dysfunction has been attributed to the increased intravesical pressure which forces the ureter to pump urine into the bladder at increasingly higher pressures until a state of hydronephrosis is reached (Butler et al., I97I). Somewhat similar conclusions were reached by Thomas et al. (1974), who found upper tract deterioration associated with spina bifida patients whose detrusor activity generated high pressures. From our patients it can be noted that voiding pressures tended to be higher than normal $(>60 \mathrm{~mm} \mathrm{Hg})$. Also the urethral resistance pressure, $P_{u}$, was higher than normal $(>50 \mathrm{~mm} \mathrm{Hg}$ ).

\section{SUMMARY}

Based on the example of these patients as well as reports of others, we believe that all patients functioning in the catheter-free state must be followed regularly at no longer than 6-month intervals. Changes in the resistance to the outflow of urine may occur at any time, even years after injury, When an event occurs, such as increased spasticity, which may be associated with increased sphincter resistance, the patient should be checked for evidence of outflow obstruction. A sterile urine is no guarantee against hydronephrotic change.

The hydronephrotic changes as demonstrated by the excretory urogram are reversible if treated early enough. Treatment consists of decreasing the outflow resistance and allowing free drainage. In our hands division of the external sphincter has usually produced the desired result. In some patients, it may be necessary to perform a bladder neck resection in addition to or in place of sphincterotomy.

\section{RÉSUMÉ}

Nous avons suivi, au cours habituels, six patients affectés d'une paralyse de la vessi suivant un lésion du moelle épinière. Ils ont tous réalizés un êtàt de sonde-libre par des moyens variés, suivant les buts limités du programme.

Ils ont passé de 6 mois jusqu'au 2 ans et demi sans aucune évaluation de leurs systems. Une seule malade a demontrée une Urographie-intravenus normale une année après l'enlevement du sonde. Deux ans après une hydronephrose bilateral s'ensuivit.

Nous discutons le dévelopment du traitment du hydronephrose chez des patients souffrant d'une vessi neurogenique sans sonde et une system pour les suivant.

\section{ZUSAMMENFASSUNG}

Sechs Patienten mit neurogenen Blasenstoerungen, die sekundaer nach Rueckenmarksverletzungen aufgetreten waren, wurden in unserer Klinik nachuntersucht. In allen 
diesen Faellen war durch verschiedene Methoden ein katheterfreier Zustand erreicht worden und sie waren ihrem Standard entsprechend, in einem guten Zustand.

Sie hatten waehrend eines Zeitraumes von 6 Monaten bis zu zweienhalb Jahren keine urologische durchgeherde Nachuntersuchung gehabt. In einem Fall zeigte sich en normales Urogramm ein Jahr nach der Katheterentfernung, und zwei Jahre spaeter wurde eine beiderseitige Hydronephrosis festgestellt.

Die Entwicklung der Hydronephrosis ohne klinische Symptome waehrend der katheterfreien Phase sowie die Behandlung und Vorschlaege fuer die Nachuntersuchung von Patienten werden diskutiert.

\section{REFERENCES}

AsCOLI, R. \& FRANCH, L. (1970). The dilation of the upper urinary tract in paraplegics. International Fournal of Paraplegia, 8, I96-I98.

Butler, E. D. JR., Friedland, G. W. \& Govan, D. (I97I). A radiological study of the effect of elevated intravesical pressure on urethral calibre and peristalsis in patients with neurogenic bladder dysfunction. Clinical Radiology, 22, 198-204.

Damanski, M. \& GibBon, H. (I956). The upper urinary tracts in the paraplegic: a long term survey. British fournal of Urology, 28, 24-36.

Hutch, J. A. \& BunTs, R. C. (I95I). The present status of the war-time paraplegic. Fournal of Urology, 66, 218-228.

Nanninga, J. B., Rosen, J. \& O’Conor, V. J., JR. (1974). Experience with transurethral external sphincterotomy in patients with spinal cord injury. Fournal of Urology, II2, 72-74.

Ross, J. CosBIE (1963). Surgical treatment of hydronephrosis in paraplegia. International Fournal of Paraplegia, I, I37-I48.

TALBOT, H. S. \& BUNTS, R. C. (I940). Late renal changes in paraplegia: hydronephrosis due to vesico-ureteral reflux. Fournal of Urology, 6I, 870-880.

Thomas, G. G., Zachary, R. B. \& Lister, J. (I974). Serial followup studies in spina bifida infants. Fournal of Pediatric Surgery, 9, 47I-476. 